Rev. Biol. Neotrop. 6(1):25-34, 2009

\title{
orfoanatomia caulinar de seis espécies de Phoradendron Nutt. (Viscaceae)
}

\author{
Greta Aline Dettke \\ Programa de Pós-graduação em Botânica, Universidade Federal do Rio Grande do Sul, Av. \\ Bento Gonçalves 9500, Agronomia, Porto Alegre, 91501-970, Rio Grande do Sul, Brasil; \\ e-mail: gretadet@yahoo.com.br
}

\section{Maria Auxiliadora Milaneze-Gutierre}

Departamento de Biologia, Universidade Estadual de Maringá, Av. Colombo, 5790, Maringá, 87020-900, Paraná, Brasil; e-mail: milaneze@uem.br

\begin{abstract}
Resumo: Neste estudo, foi realizada a análise morfoanatômica do caule de seis espécies de hemiparasitas (Phoradendron, Viscaceae) ocorrentes no município de Maringá, Paraná. Dependendo da espécie, o caule apresenta em seção transversal formato circular, losangular com expansões nos vértices ou quadrangular. $O$ caule apresenta-se recoberto por cutícula fina; as células epidérmicas formam papilas pouco ou bastante proeminentes, dependendo da espécie; possuem as paredes anticlinais e periclinais externas espessas e cutinizadas. Após crescimento secundário acentuado, esse revestimento cutinizado pode se romper, formando uma região de cicatrização; a presença de papilas auxilia no crescimento em diâmetro. O parênquima cortical é fotossintético, possui braquiesclereídes, idioblastos cristalíferos e secretores de compostos fenólicos, além de acumular substâncias lipídicas. Os feixes vasculares apresentam crescimento secundário já nos primeiros entrenós, formando, em seguida, um sistema vascular compacto, com raios portando grande quantidade de amiloplastos. Do floema e xilema primários derivam calotas de fibras. A medula, inicialmente parenquimática, tornase esclerificada, portando cristais, amido e grandes grupos de braquiesclereídes. O formato do caule, em seção transversal, é a característica mais indicada para fins taxonômicos, sendo as características anatômicas complementares.
\end{abstract}

Palavras-chave: Anatomia vegetal, crescimento secundário, hemiparasitas, Phoradendron, Viscaceae.

\section{Stem morphoanatomy of six species of Phoradendron Nutt. (Viscaceae)}

Aвstract: In this study, we analyzed the morphology and anatomy of stems of six mistletoe species (Phoradendron, Viscaceae) in Maringá, in the state of Paraná. According to the species, the stem may present several shapes in transversal section: circular, losangular with expansions in the extremities or square. The stem is covered with a thin cuticle; epidermic cells form a papilose surface, little or very prominent depending on the species; they present external anticlinal and periclinal very thick and cutinized walls. After secondary growth, this walls and cuticle can break up, forming a cicatrization tissue area; papilose epidermis may help in the extension growth. Cortical parenchyma is photosynthetic and presents brachysclereids, idioblasts with crystals, phenolic and lipidic substances and also accumulates lipids. Vascular bundles present secondary growth even in the first internodes, originating a compact vascular system with rays containing abundant amyloplasts. The primary phloem and xylem form fibers. The pith initially parenchymatous becomes sclerified with crystals, starch and brachysclereids groups. The shape of the stem in a cross section is the most suitable feature for taxonomic purposes, whereas the anatomical characters complement this.

Key words: Plant anatomy, secondary growth, mistletoe, Phoradendron, Viscaceae. 


\section{INTRODUÇÃO}

s espécies hemiparasitas de ra-
mos aéreos, objeto deste estu-
do, são popularmente denominadas ervas-de-passarinho e distribuem-se nas famílias Santalaceae, Misodendraceae, Loranthaceae e Viscaceae, pertencentes à ordem Santalales, somando cerca de 1.500 espécies (Nickrent, 1997). Viscaceae conta com 546 espécies, sendo Phoradendron o maior gênero, com 234 espécies (Der \& Nickrent, 2008; Kuijt, 2003). Esse gênero possui distribuição restrita ao continente americano e, de acordo com Rizzini (1978), a maior diversidade de espécies encontra-se na América do Sul. No Brasil, ocorrem cerca de 200 espécies de hemiparasitas aéreas, sendo Phoradendron um dos gêneros mais ricos, com aproximadamente 80 espécies (Kuijt, 2003).

Quanto ao habitat, tais espécies ocorrem em ambientes tão diversos quanto desertos e florestas tropicais, parasitando diversas espécies de angiospermas. No Brasil, Rizzini (1968) relatou que as hemiparasitas são heliófitas e ocupam o dossel das matas, recebendo maior insolação, sendo poucas as formas esciófitas, do interior da floresta, as quais assumem coloração verde mais intensa. Ainda segundo o mesmo autor, tais plantas manifestam esclerofilia, sendo comuns espécies providas de folhas grossas, duras ou suculentas e ramos fortemente lignificados.

Pelo fato da evolução desse grupo estar fortemente relacionada a uma progressiva redução do androceu e do gineceu, os órgãos reprodutivos (propriamente a flor), são pouco informativos em fins taxonômicos, ou apresentam alta variabilidade intraespecífica, como no caso da posição das flores nas inflorescências (Ashworth, 2000). Assim, os estudos morfológicos e anatômicos dos órgãos vegetativos tornam-se essenciais para o grupo, pois fornecem características que auxiliam na determinação das espécies.

No Brasil, são relativamente raros os trabalhos anatômicos enfocando tais espécies, principalmente se considerada a alta diversidade existente. Nesse sentido, destaca-se apenas Struthantus vulgaris (Loranthaceae), estudada por Venturelli $(1980,1984 b)$. Em relação à família Viscaceae no Brasil, apenas o trabalho de Rizzini (1950), sobre Phoradendron fragile, e os de Dettke \& Milaneze-Gutierre (2007) e Ferreira et al. (2007), ambos sobre Phoradendron mucronatum, são referenciados na literatura. Rizzini (1978) destacou a importância de características como o formato do caule e o comprimento dos entrenós para a identificação de espécies de Phoradendron, as quais, de acordo com o autor, são mais constantes para fins de identificação. Rizzini (1978) ainda aconselhou que sejam realizadas seções anatômicas para a sua real compreensão.

Este estudo teve o objetivo de analisar aspectos morfoanatômicos do caule de espécies de Phoradendron (Viscaceae) ocorrentes no município de Maringá, Paraná, como uma contribuição ao conhecimento destas espécies no Brasil. Também contribui fornecendo elementos para auxiliar a identificação de espécies dessa família por meio de caracteres vegetativos e como subsídio para futuros estudos de ecofisiologia e metabolismo dessas plantas.

\section{Material e métodos}

Todo o material utilizado neste estudo proveio de espécimes ocorrentes no município de Maringá, mais especificamente do Parque do Ingá, um fragmento de Floresta Estacional Semidecidual localizado na região central da cidade, e do Campus Sede da Universidade Estadual de Maringá. Salienta-se que essas espécies também são ocorrentes na arborização urbana e em outros fragmentos florestais da região e suas amostras encontram-se depositadas no Herbário da Universidade Estadual de Maringá (HUEM).

Foram analisados os caules das seguintes espécies de Phoradendron Nutt.: P. obtusissimum (Miq.) Eichler, P. linearifolium Eichler, P. mucronatum (DC.) Krug \& Urb., P. perrottetii (DC.) Eichler, P. piperoides (Kunth) Trel. e P. quadrangulare (Kunth) Griseb., estando as amostrastestemunho sob registros 11834, 11619, 11404, 11402, 11620 e 11403, respectivamente.

Para a análise anatômica, foram utilizados caules em diferentes estádios de desenvolvimento, do primeiro ao quarto entrenó (denominados caules jovens) e entrenós próximos à inserção no hospedeiro (denominados 
caules maduros) de, no mínimo, quatro indivíduos de cada espécie. Foi utilizado material fresco ou fixado em FAA 50 e, posteriormente, transferido para álcool 70\% para conservação.

As seções anatômicas foram elaboradas à mão livre, com auxílio de lâmina de barbear, nos planos transversal, tangencial e radial. Essas foram diafanizadas com hipoclorito de sódio 33\%, lavadas em água destilada e submetidas ao processo de dupla coloração com azul de astra e safranina (Kraus \& Arduin, 1997). A seguir, foram montadas em gelatina glicerinada como lâminas semipermanentes. Para a análise do formato das células individualizadas, amostras de material vegetativo foram maceradas, seguindo as indicações de Kraus \& Arduin (1997).

Os testes microquímicos foram realizados em seções obtidas à mão livre em materiais frescos. A ocorrência de substâncias pécticas foi detectada utilizando-se vermelho de rutênio (Strasburger, 1924); a de substâncias fenólicas por cloreto férrico 10\%; a cutina, usando Sudan IV (Johansen, 1940); a lignina foi identificada com floroglucina em meio ácido; o amido, pelo lugol (Sass, 1951); o oxalato de cálcio foi revelado pela ação do cloral hidratado $60 \%$ em solução com ácido sulfúrico $25 \%$ em etanol absoluto e a celulose e a lignina, diferenciadas pelo cloreto de zinco iodado (Kraus \& Arduin, 1997).

As ilustrações foram obtidas com auxílio de câmara clara acoplada ao microscópio óptico ou microscópio estereoscópico; as fotomicrografias foram obtidas com fotomicroscó- pio Olympus (modelo BX51), utilizando para a captação de imagens o software Image Pro Express.

\section{Resultados}

\section{MORFOLOGIA CAULINAR}

Os caules das espécies de Phoradendron têm entrenós variando entre $2 \mathrm{~cm}$ e $11 \mathrm{~cm}$, nas regiões totalmente expandidas, e somente $P$. perrottetii possui entrenós maiores do que $8 \mathrm{~cm}$ (Tabela 1).

Em seção transversal, os caules apresentam formato único, tal como circular em P. obtusissimum (Figura 1A), P. linearifolium (Figura 1B) e P. piperoides (Figura 1E) e losangular com expansões nos vértices como em $P$. mucronatum (Figura 1C); ou com mais de um formato. $P$. perrottetii apresenta ramos com formato circular e ramos com formato aproximadamente losangular em seção transversal (Figura 1D). P. quadrangulare apresenta, em um mesmo ramo, formatos circulares e quadrangulares. Estes últimos, após crescimento secundário, tornam-se aproximadamente circulares ou levemente comprimidos (Figura 1F).

\section{Anatomia caulinar}

Os diversos estádios de desenvolvimento dos tecidos caulinares das espécies estudadas estão representados nas Figuras 1A-F.

Em vista frontal, as células epidérmicas são quadrangulares ou pentagonais irregulares, com paredes retas ou pouco curvas

Tabela 1 - Características morfoanatômicas distintivas do caule de espécies de Phoradendron (Viscaceae).

\begin{tabular}{lcccc}
\hline Característica & $\begin{array}{c}\text { Comprimento do } \\
\text { entrenó } \mathbf{( c m})\end{array}$ & $\begin{array}{c}\text { Formato do } \\
\text { caule }\end{array}$ & $\begin{array}{c}\text { Papilas pronunciadas } \\
\text { no caule }\end{array}$ & $\begin{array}{c}\text { Estratos corticais } \\
\text { do caule }\end{array}$ \\
\hline P. linearifolium & $5-8$ & Circular & Pouco & $7-10$ \\
P. mucronatum & $3-7$ & $\begin{array}{c}\text { Losangular } \\
\text { Circular }\end{array}$ & Sim & $3-5$ \\
P. obtusissimum & $2-5$ & Sim & $5-8$ \\
P. perrottetii & $8-11$ & $\begin{array}{c}\text { Circular ou } \\
\text { losangular }\end{array}$ & Sim & $6-8$ \\
P. piperoides & $5-8$ & Circular & Pouco & $6-8$ \\
P. quadrangulare & $3-6$ & $\begin{array}{c}\text { Circular ou } \\
\text { quadrangular }\end{array}$ & Sim & $5-8$ \\
\hline
\end{tabular}




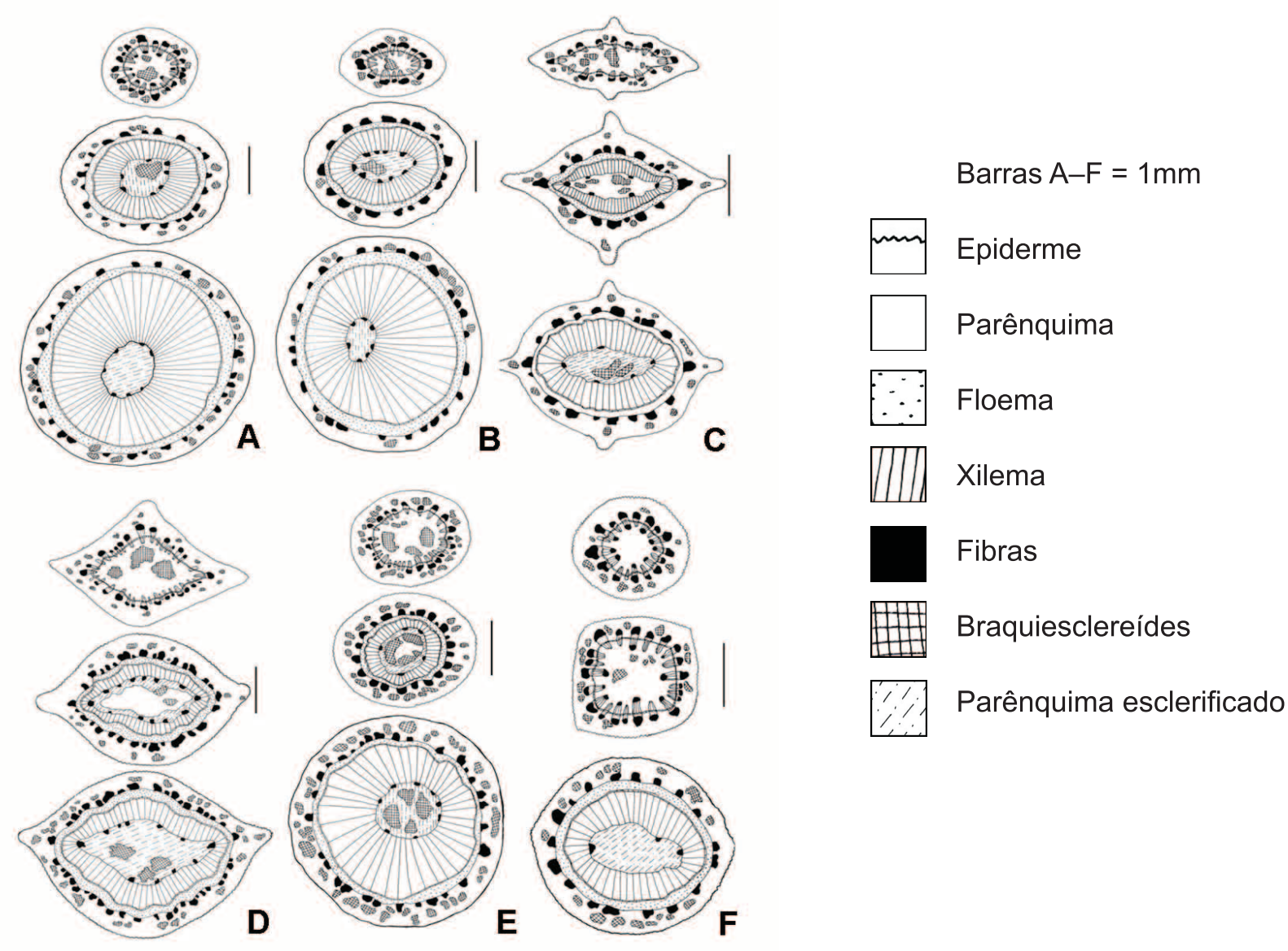

Figura 1 - Diagramas do desenvolvimento dos tecidos caulinares em espécies de Phoradendron, do primeiro, segundo e após o quarto entrenó, respectivamente. A. P. obtusissimum; B. P. linearifolium; C. $P$. mucronatum; D. P. perrottetii; E. P. piperoides; F. P. quadrangulare.

(Figura 2A), tornando-se alongadas anticlinalmente, acompanhando a expansão do caule. Os estômatos são paracíticos e estão orientados transversalmente em relação ao eixo (Figura 2A). No entanto, em algumas regiões do caule de P. perrottetii, os estômatos encontramse distribuídos aleatoriamente. A cutícula que reveste esse órgão é delgada e as paredes periclinais externas das células epidérmicas são espessas e cutinizadas, assim como as paredes anticlinais, que formam flanges pronunciadas (Figuras 2B-F). A espessura da parede periclinal externa pode variar entre $10 \mu \mathrm{m}$ a $25 \mu \mathrm{m}$ nos caules em estádios jovens.

Ainda nos estádios jovens, a epiderme forma papilas muito proeminentes em P. obtusissimum, P. mucronatum (Figuras 2B e 2F), P. perrottetii (Figuras 2D e 2E) e P. quadrangulare ou papilas menores em $P$. linearifolium e P. piperoides (Tabela 1). Assim como os estratos subepidérmicos, a epiderme possui substân- cias lipídicas armazenadas no interior celular, porém em maior quantidade, como pôde ser visualizado, após teste microquímico com Sudan IV, em P. obtusissimum e P. perrottetii (Figura 2E).

A região cortical é constituída por parênquima homogêneo (Figuras 2C-F), sendo os estratos mais externos (um a quatro) portadores de cloroplastídeos. O número de estratos celulares varia conforme a espécie, entre três e dez estratos, conforme apresentado na Tabela 1.

Em todas as espécies estudadas, o sistema vascular do caule em estrutura primária é formado por feixes do tipo colateral com organização eustélica (Figura 3A). A medula é parenquimática e suas células, aproximadamente isodiamétricas, são maiores do que as corticais (Figuras 3A, 3D e 3E).

No caule jovem (primeiro entrenó) dessas espécies de hemiparasitas, é possível in- 


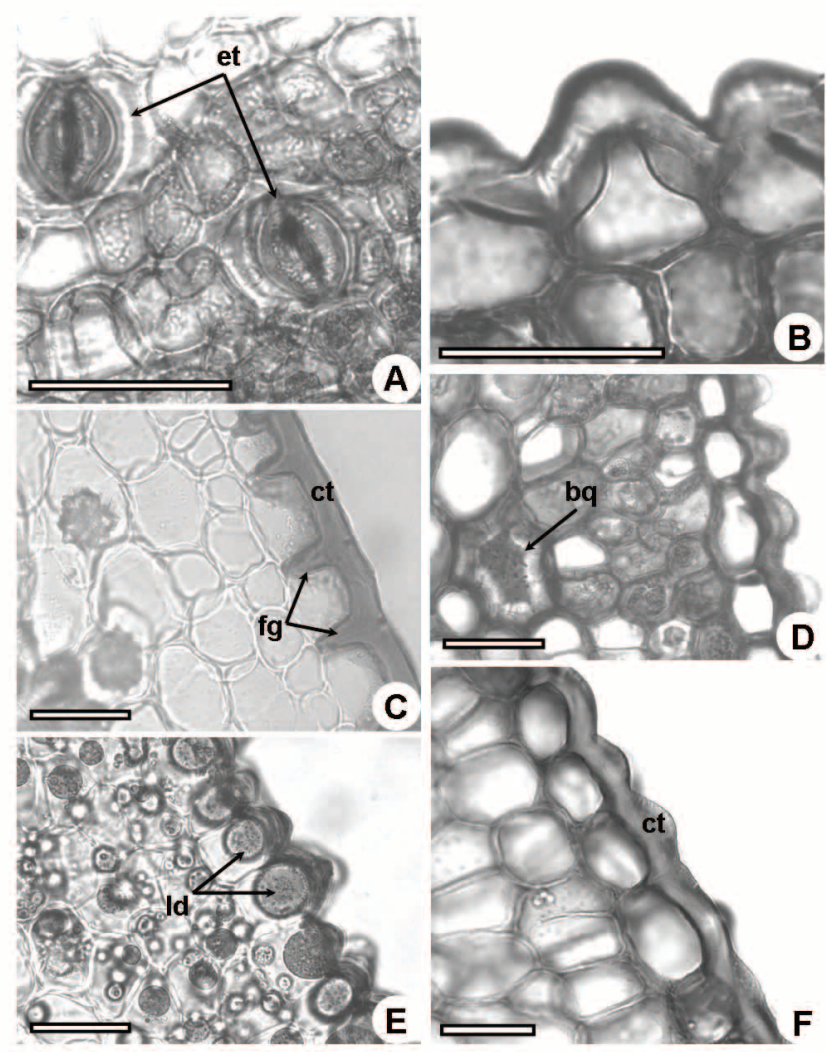

Figura 2 - Seções do caule de espécies de Phoradendron: A. Seção paradérmica do caule jovem de $P$. linearifolium; B. Seção transversal da epiderme do caule de $P$. linearifolium - detalhe de uma papila; C. Seção transversal do caule jovem de $P$. piperoides - detalhe da epiderme e parênquima cortical; D. Seção transversal do caule jovem de $P$. perrottetii - detalhe da epiderme com papilas muito proeminentes; E. Seção transversal do caule jovem de $P$. perrottetii submetida ao reagente Sudan IV, evidenciando gotas lipídicas; F. Seção transversal do caule jovem de $P$. mucronatum - detalhe da epiderme com papilas. bq: braquiesclereídes; ct: revestimento cutinizado; et: estômato; fg: flanges; Id: gotas lipídicas. Barras: B-F = $50 \mu \mathrm{m} ; \mathrm{A}=100 \mu \mathrm{m}$.

dividualizar os feixes vasculares com a presença de câmbio vascular (Figuras 3A e 3B). Nesse estádio, as células do floema primário possuem paredes constituídas principalmente por celulose e substâncias pécticas (Figura 3B); nos estádios posteriores, ocorre deposição de lignina nas paredes, configurando fibras (Figuras 3C-E). Depois de acentuado crescimento secundário, as paredes das células dos raios parenquimáticos do xilema tornam-se lignificadas, assim como o parênquima medular (Figuras 3D e 3E).

O xilema primário das espécies de Phoradendron é composto por elementos traqueais com espessamento anelar e helicoidal (Figura 4A). No xilema secundário, os elementos de vaso têm parede pontuada e placas de perfuração simples (Figura 4B), transversais ou oblíquas (Figura 4C). Grandes quantidades de fibras libriformes de paredes espessas também compõem o xilema secundário, entreme- ando os elementos de vaso (Figura 4D). Essas fibras possuem crescimento intrusivo e, frequentemente, quando analisado material dissociado, apresentam projeções nas paredes, que representam o local de contato com as células parenquimáticas. Nos caules que possuem formato circular, em seção transversal, observa-se maior incremento de xilema secundário em relação aos outros formatos, quando analisados no mesmo nível de entrenó (Figuras $1 \mathrm{~A}-\mathrm{F})$.

Além de substâncias lipídicas, foram registrados grãos de amido de formato esférico nas células parenquimáticas com paredes lignificadas dos raios e da medula (Figuras $4 \mathrm{~A}$ e 4C). Tanto na medula como no córtex dos caules maduros dessas espécies é frequente a ocorrência de braquiesclereídes em grandes grupos, especialmente na medula (Figuras 2D, $3 C$ e 5A-B). Grupos menores, de duas a cinco células, encontram-se no parênquima cortical 


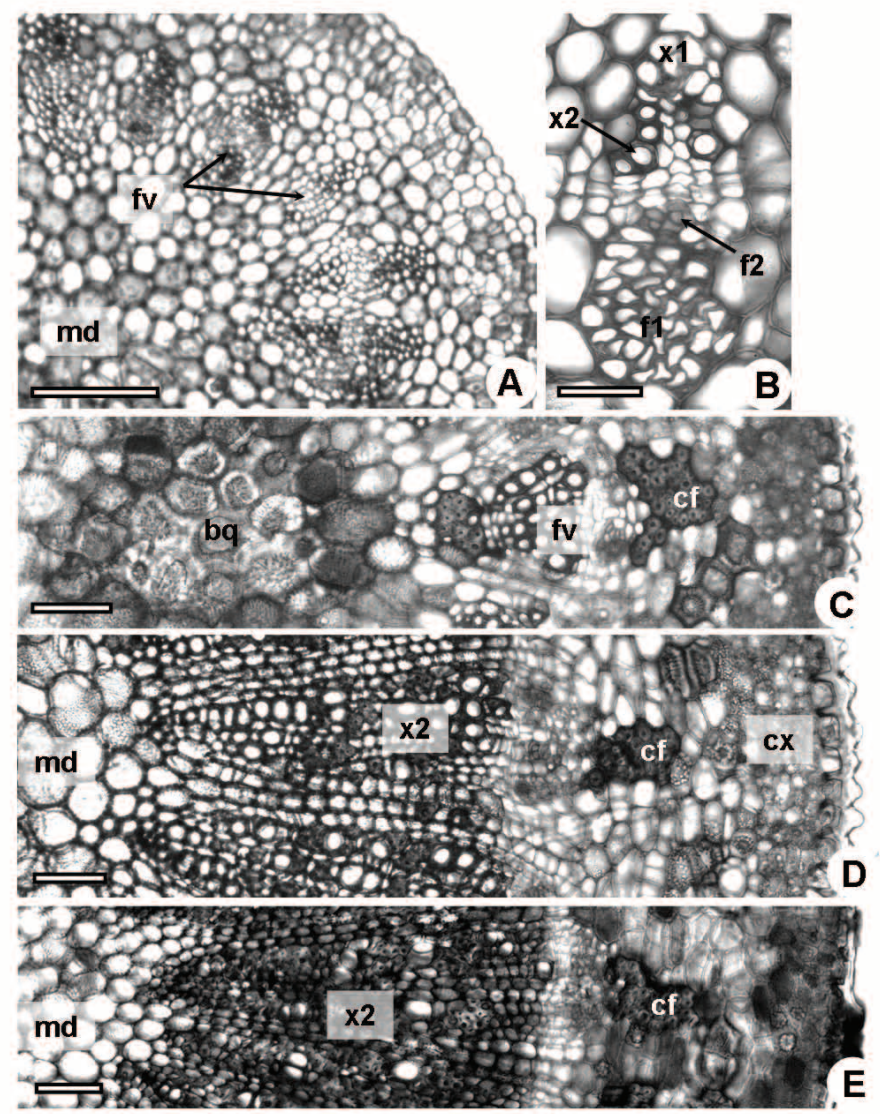

Figura 3 - Seções transversais do caule jovem e maduro de espécies de Phoradendron: A-B. Caule de $P$. quadrangulare - primeiro entrenó; A. Aspecto geral; B. Detalhe do feixe vascular em início de crescimento secundário; C. Caule de $P$. obtusissimum - segundo entrenó, D. Caule de $P$. obtusissimum - terceiro entrenó; E. Caule de $P$. piperoides - quarto entrenó. bq: braquiesclereides; cf: calota de fibras do floema; cx: córtex; f1: floema primário; f2: floema secundário; fv: feixes vasculares; md: medula; x1: xilema primário; x2: xilema secundário. Barras: $B=50 \mu \mathrm{m} ; \mathrm{C}-\mathrm{E}=100 \mu \mathrm{m} ; \mathrm{A}=200 \mu \mathrm{m}$.

(Figura 5C). Essas células adquirem espessamento parietal e impregnação por lignina logo no início do desenvolvimento do caule e as pontoações são frequentemente ramificadas (Figura 5C).

Idioblastos com drusas também são abundantes, principalmente na região cortical (Figura 2C) e estratos periféricos da medula. Compostos fenólicos foram localizados, sobretudo, nas células do parênquima cortical.

Os caules das espécies de Phoradendron analisadas no presente estudo não formam periderme, mesmo após ter alcançado diâmetro considerável com o crescimento secundário (cerca de $3 \mathrm{~cm}$, próximo à inserção com o hospedeiro). Nessa condição, as paredes periclinais externas das células epidérmicas, juntamente com a cutícula, tornam-se bastante espessas, atingindo até $70 \mu \mathrm{m}$ (Figuras 5D-F). Por vezes, esse revestimento se rompe, formando uma região de cicatrização, rica em substâncias lipídicas (Figura 5D).

Para acompanhar o crescimento radial, as células do parênquima cortical se dividem intensamente no plano anticlinal, o que é bem visualizado pelas paredes celulares finas, em estratos radialmente contínuos (Figuras 5D e $5 F)$. Não foram observadas divisões nas células epidérmicas, que acompanham esse crescimento expandindo suas células papilosas, tornando-se achatadas (Figura 5E).

\section{Discussão}

Caracteres como o formato do caule e o comprimento dos entrenós, de acordo com Rizzini (1978), são mais constantes para fins de identificação de espécies de Phoradendron. Quanto ao comprimento dos entrenós, somente $P$. perrottetii se destaca das demais es- 


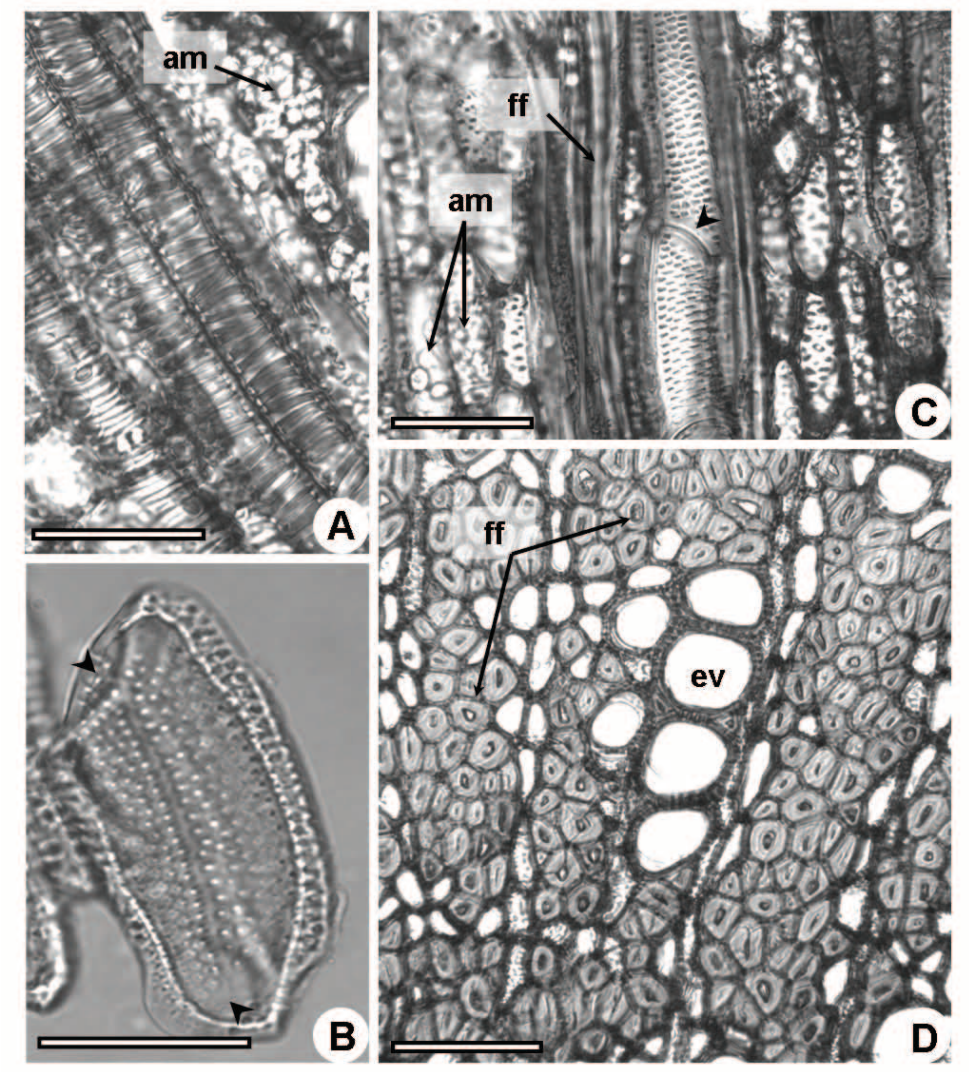

Figura 4 - Seções do caule jovem e maduro de espécies de Phoradendron: A. Seção longitudinal tangencial do caule de $P$. quadrangulare - xilema primário mostrando elementos traqueais com espessamento helicoidal; B. Macerado do caule de $P$. quadrangulare - elemento de vaso do xilema secundário com placas de perfuração simples (cabeça de setas); C. Seção longitudinal tangencial do caule de $P$. obtusissimum - xilema secundário evidenciando fibras e elementos de vaso com espessamentos dos tipos reticulado e pontoado com placa de perfuração oblíqua (cabeça de seta); D. Seção transversal do caule de $P$. linearifolium - xilema secundário evidenciando fibras e elementos de vaso. am: grãos de amido; ev: elemento de vaso; ff: fibras. Barras: $\mathrm{A}-\mathrm{C}=50 \mu \mathrm{m} ; \mathrm{D}=100 \mu \mathrm{m}$.

pécies, com entrenós mais longos. Os caules de P. obtusissimum, P. linearifolium e P. piperoides têm formato circular, P. mucronatum tem caule de formato losangular, $P$. perrottetii e $P$. quadrangulare apresentam caules circulares ou quadrangulares, revelando a importância deste caráter para a sua distinção. No entanto, deve-se tomar cuidado quanto ao estádio de desenvolvimento do caule, já que com o crescimento secundário avançado, a tendência é que o órgão torne-se cilíndrico, como observado na região de inserção com o hospedeiro nas espécies analisadas.

No caule, a epiderme forma papilas, sendo muito ou pouco proeminente, dependendo da espécie. Essa característica permite a distinção de dois grupos entre as espécies estudadas, quando considerados caules jovens: um grupo em que as papilas epidérmicas são sempre bem proeminentes, como em
P. obtusissimum, P. mucronatum, P. perrottetii e $P$. quadrangulare, e outro em que as papilas são pouco proeminentes, como em $P$. linearifolium e P. piperoides. Nas espécies analisadas, as papilas epidérmicas têm função adicional no crescimento secundário do caule, permitindo o crescimento em diâmetro, fato até então não relatado para espécies de Santalales.

Em Phoradendron fragile, Rizzini (1950) destacou a presença de substâncias pécticas perto da "cutícula" que forma as papilas. Nas espécies estudadas, a porção referida pelo autor corresponde à parede periclinal externa espessa e cutinizada das células epidérmicas. Neste estudo, as substâncias pécticas foram detectadas principalmente na parede primária das células epidérmicas.

No caule dessas espécies, os estômatos possuem orientação transversal em relação ao eixo axial, o que confirma as observa- 


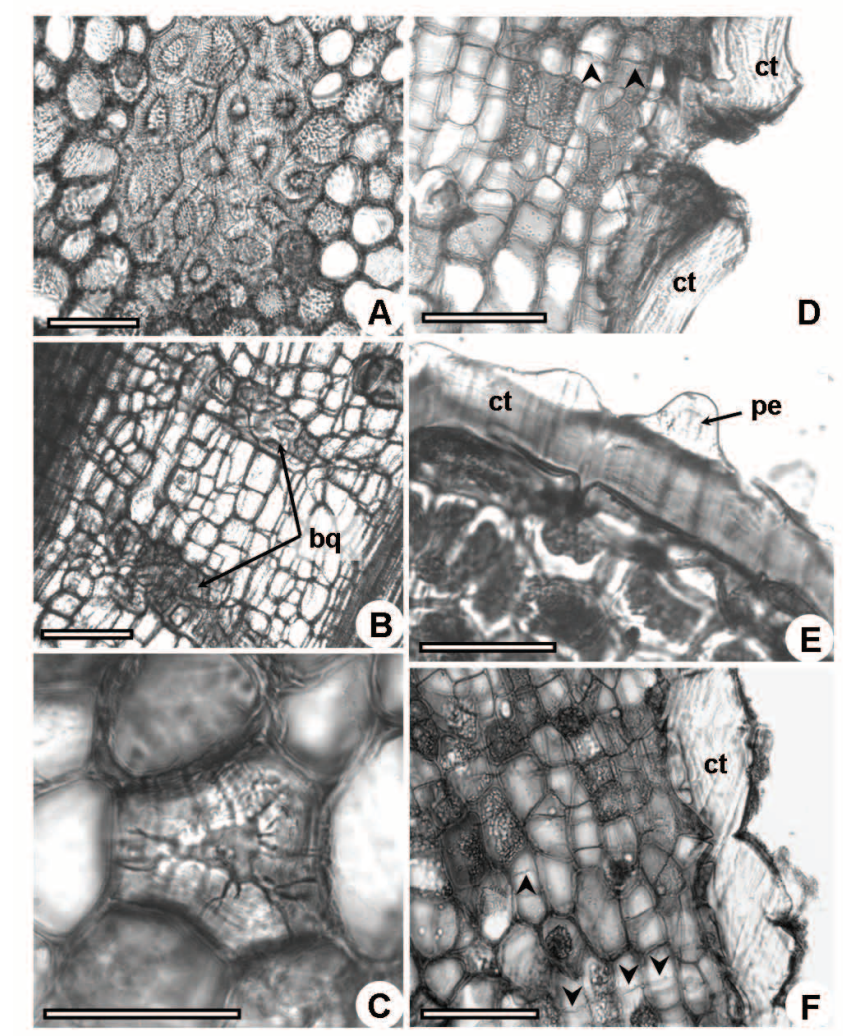

Figura 5 - Seções do caule maduro de espécies de Phoradendron: A. Seção transversal do caule de P. perrottetii evidenciando um grande grupo de braquiesclereides na região medular; B. Seção longitudinal radial do caule de P. piperoides evidenciando grupos de braquiesclereídes na medula; C. Seção transversal do caule de P. quadrangulare evidenciando braquiesclereíde isolada, com pontoações ramificadas, na região cortical; D. Seção transversal do caule de P. linearifolium evidenciando o revestimento rompido e células do parênquima cortical se dividindo no plano anticlinal (setas); E. Seção transversal do caule de P. mucronatum; F. Seção transversal do caule de P. obtusissimum evidenciando divisões celulares no parênquima cortical (cabeças de setas). bq: braquiesclereídes; ct: revestimento cutinizado; pe: papila epidérmica. Barras: $A, C, E=50 \mu \mathrm{m} ; B, F=100 \mu \mathrm{m} ; B=200 \mu \mathrm{m}$.

ções de Wilson \& Calvin (2003). No entanto, P. perrottetii também apresentou estômatos orientados aleatoriamente em algumas regiões da epiderme.

Nas células parenquimáticas do córtex caulinar, são comuns gotículas lipídicas como substância de reserva, principalmente nos estádios jovens, ocupando quase todo o interior celular. Também há grande quantidade de compostos fenólicos no caule dessas espécies, fato já constatado nos órgãos vegetativos de outras espécies de Viscaceae e Loranthaceae e que teria relação com os hospedeiros destas espécies (Ashworth, 1997; Cannon, 1901; Carlquist, 1985; Hauenstein et al., 1990; Metcalfe \& Chalk, 1979; Rizzini, 1950; Varela \& Gurni, 1995; Venturelli, 1984b; York, 1909). Não foram encontrados canais secretores de mucilagem, como os relatados por Metcalfe \& Chalk (1979) para P. crassifolium.
A grande quantidade de idioblastos com cristais de oxalato de cálcio, como relatado neste estudo, é frequente em todos os órgãos vegetativos e reprodutivos de espécies de hemiparasitas, assim como as braquiesclereídes ou células pétreas (Ashworth \& Santos, 1997; Cannon, 1901; Carlquist, 1985; Hauenstein et al., 1990; Metcalfe \& Chalk, 1979; Rizzini, 1950; Varela \& Gurni, 1995; Venturelli, 1981, 1984a,b; York, 1909).

Em todas as espécies estudadas, o esclerênquima, adjacente aos feixes vasculares, consiste de fibras derivadas do floema primário e xilema primário e secundário, como também foi comprovado por Calvin (1967) em $P$. flavescens. De acordo com o autor, essas fibras possuem crescimento intrusivo, muitas vezes em ambas as extremidades, e possuem características projeções das paredes, como observado nas espécies em estudo, que repre- 
sentam o contato destas células com as demais adjacentes.

Os caules das espécies de Phoradendron analisadas não formam periderme. Esse fato, também observado por Wilson \& Calvin (2003), parece ser característico da ordem Santalales. No entanto, são necessários mais estudos com outras espécies para afirmar que essa seria uma sinapomorfia do grupo.

Metcalfe \& Chalk (1979) citaram que alguns gêneros podem ter espécies que formam um "súber superficial", tais como Loranthus, Nuytsia (Loranthaceae) e Phoradendron (Viscaceae), especialmente P. crassifolium. Para outras espécies, nas quais não há formação desse tecido, os autores denominaram os estratos superficiais do caule maduro de "epitélio cuticular", que seria formado pela epiderme e outros estratos corticais, nos quais as paredes se tornam espessas.

"Súber superficial" ou epitélio cuticular, tais como descritos por Metcalfe \& Chalk (1979), não foram observados nas espécies em estudo. Nestas, percebe-se que as paredes periclinais externas das células epidérmicas tornam-se progressivamente espessas e as células do parênquima cortical se dividem radialmente, permanecendo com paredes finas, diferentemente do conceito de "súber superficial", no qual as células subjacentes à epiderme seriam espessas e suberificadas.

Da mesma forma que as folhas (Dettke \& Milaneze-Gutierre, dados não publicados), os caules de Phoradendron analisados fornecem poucos elementos anatômicos que permitem distinção segura entre as espécies. Assim, os aspectos morfológicos seriam os mais indicados para esse fim, tal como o formato do caule em seção transversal, desde que observado seu estádio de desenvolvimento.

\section{Agradecimentos}

Agradecemos ao Prof. Dr. Fábio Amodeo Lânsac-Toha e ao biólogo Dr. Luiz Felipe Machado Velho (Laboratório de Zooplâncton, Nupélia/UEM) pela concessão do fotomicroscópio, e aos Prof. Dr. Luiz Antonio de Souza e Prof. Dr. Ismar Sebastião Moscheta (Departamento de Biologia/UEM) pelas valiosas sugestões.

\section{ReferênCIAS}

Ashworth, V. E. T. M. 1997. Transectional anatomy of leaves and young stems of mistletoe genus Phoradendron Nutt. (Viscaceae). Amer. J. Bot. 84: 174.

Ashworth, V. E. T. M. 2000. Phylogenetic relationships in Phoradendreae (Viscaceae) inferred from three regions of the nuclear ribosomal cistron. I. Major lineages and paraphyly of Phoradendron. Syst. Bot. 25: 349-370.

Ashworth, V. E. T. M. \& G. Santos. 1997. Wood anatomy of four californian mistletoe species (Phoradendron, Viscaceae). IAWA J. 18: 229-245.

Calvin, C. L. 1967. The vascular tissues and development of sclerenchyma in the stem of the mistletoe, Phoradendron flavences. Bot. Gaz. 128: 35-59.

Cannon, W. A. 1901. The anatomy of Phoradendron villosum Nutt. Bull. Torrey Bot. Club. 28: 374-399.

Carlquist, S. 1985. Wood and stem anatomy of Misodendraceae: systematic and ecological conclusions. Brittonia 37: 58-75.

Der, J. P. \& D. L. Nickrent. 2008. A molecular phylogeny of Santalaceae (Santalales). Syst. Bot. 33: 107-116.

Dettke, G. A. \& M. A. Milaneze-Gutierre. 2007. Estudo anatômico dos órgãos vegetativos da hemiparasita Phoradendron mucronatum (DC.) Krug \& Urb. (Viscaceae). Rev. Bras. Bioc. 5: 534-536.

Ferreira, C. P., H. S. Xavier \& R.M.M. Pimentel. 2007. Estudo morfoanatômico foliar de Phoradendron mucronatum (D.C.) Krug. \& Urb. Rev. Bras. Bioc. 5: 708-710.

Hauenstein, E, V. Arriagada \& M. Latsague. 1990. La epidermis foliar de las Loranthaceae chilenas y su relación con la ecología. Darwiniana 30: 143-153.

Johansen, D. A. 1940. Plant microtechnique. McGraw-Hill, New York.

Kraus, J. E. \& M. Arduim. 1997. Manual básico de método em morfologia vegetal. EDUR (Editora Universidade Rural), Rio de Janeiro. 
Kuijt, J. 2003. Monograph of Phoradendron (Viscaceae). Syst. Bot. Monogr. 66: 1-643.

Metcalfe, C. R. \& L. Chalk. 1979. Loranthaceae. p.1 188-1194. In: C. R. Metcalfe \& L. Chalk (Eds.), Anatomy of the Dicotyledons. Oxford, Clarendon Press.

Nickrent, D. L. 1997. The parasitic plant connection. Disponível em: http://www. parasiticplants.siu.edu/.

Rizzini, C. T. 1950. Sobre Phoradendron fragile Urb. Rev. Bras. Biol. 10: 45-58.

Rizzini, C. T. 1968. Lorantáceas catarinenses, p. 1-44. In: R. Reitz (Ed.) Flora ilustrada catarinense. Itajaí, Herbário Barbosa Rodrigues.

Rizzini, C. T. 1978. El género Phoradendron en Venezuela. Rodriguesia 46: 33-125.

Sass, J. E. 1951. Botanical microtechnique. The Iowa State College Press, Ames.

Strasburger, E. 1924. Handbook of practical botany. MacMillan Company, New York.

Varela, B. G. \& A. A. Gurni. 1995. Anatomía foliar y caulinar comparativa del muérdago criollo y del muérdago europeo. Acta Farm. Bonaer. 14: 21-29.
Venturelli, M. 1980. Desenvolvimento anatômico do haustório primário de Struthanthus vulgaris Mart. Bol. Bot. USP 8: 47-64.

Venturelli, M. 1981. Estudos sobre Struthanthus vulgaris Mart.: anatomia do fruto e semente e aspectos de germinação, crescimento e desenvolvimento. Rev. Bras. Bot. 4: 131-147.

Venturelli, M. 1984a. Estudos embriológicos em Loranthaceae: Struthanthus flexicaulis Mart. Rev. Bras. Bot. 7: 107-119.

Venturelli, M. 1984b. Estudos sobre Struthanthus vulgaris Mart.: aspectos anatômicos de raiz adventícia, caule e folha. Rev. Bras. Bot. 7: 79-89.

Wilson, C. A. \& C. L. Calvin. 2003. Development, taxonomic significance and ecological role of the cuticular epithelium in the Santalales. IAWA J. 24: 129-138.

York, H. H. 1909. The anatomy and some of the biological aspects of the "American mistletoe" (Phoradendron flavescens (Pursh). Nutt. Bull. Univ. Texas 120: 5-31.

Recebido em 2/V/2008

Aceito em 16/VII/2010 